УДК 616.895.4:616.89-008.485

Для цитирования: Деменева А.А., Ретюнский К.Ю. Психопатологическая дифференциация деперсонализационных расстройств при эндогенной депрессии. Сибирский вестник психиатрии и наркологии. 2017; 4 (97): 31-37. https://doi.org/10.26617/1810-3111-2017-4(97)-31-37

\title{
Психопатологическая дифференциация деперсонализационных расстройств при эндогенной депрессии
}

\author{
Деменева А.А. ${ }^{1}$, Ретюнский К.Ю. ${ }^{2}$ \\ ${ }^{1}$ Свердловская областная клиническая психиатрическая больница \\ Россия, 620030, Екатеринбург, Сибирский тракт, 8 км \\ 2 Уральский государственный медицинский университет \\ Россия, 620028, Екатеринбург, ул. Репина, д. 3
}

\section{PEЗЮME}

Цель - установление психопатологической структуры эндогенных депрессий с деперсонализационными расстройствами, разработка их типологии, выявление связи явлений деперсонализации с другими психопатологическими феноменами. Материал и методы. Исследование проводилось с 2006 по 2014 г. на базе отдела по изучению эндогенных психических расстройств и аффективных состояний Научного центра психического здоровья и на кафедре психиатрии. Критерием отбора больных служило наличие деперсонализационных расстройств в клинической картине эндогенных депрессий (F31-34). Клинико-психопатологическим и клинико-катамнестическими методами обследованы 57 пациентов (38 женщин

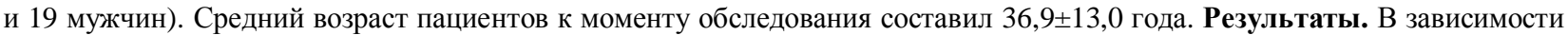
от клинико-динамических характеристик деперсонализационных расстройств в рамках эндогенных депрессий выделены 3 типологических варианта исследуемых состояний: пароксизмальный, затяжной и хронический.

\section{Ключевые слова: эндогенная депрессия, деперсонализация, типология, динамика.}

\section{ВВЕДЕНИЕ}

Анализ эпидемиологических исследований последнего времени указывает на тенденцию к неуклонному росту депрессивных расстройств. По прогнозам экспертов ВОЗ, к 2020 г. униполярная депрессия не только в странах Европы и Северной Америки, но и во всем мире займет второе место среди заболеваний, приводящих к временной потере трудоспособности. В последние годы также отмечается рост распространенности депрессивных расстройств во всех возрастных группах, при этом у женщин этот показатель в среднем в 1,5-2,5 раза больше, чем у мужчин [28].

Многочисленные исследования показывают высокий процент (как минимум около 12\%) случаев затяжного течения (хронификации) острых депрессивных эпизодов [22]. Депрессивные расстройства характеризуются разнообразием клинических фенотипов депрессии, которые нередко накладываются друг на друга [19].

Проблема деперсонализационных расстройств остается одной из наиболее актуальных в современной психиатрии. Интерес исследователей обусловлен, в первую очередь, недостаточной изученностью феномена деперсонализации, сложностью феноменологии и психопатологической дифференциации. Следует отметить и высокую терапевтическую резистентность указанной патологии к имеющимся методам лечения. С момента их выделения деперсонализационные расстройства являются объектом пристального внимания не только психиатров, но и психологов, философов, социологов. К сожалению, отсутствует единство взглядов на механизмы возникновения деперсонализации, правомерность отнесения к той или иной классификационной группе психических расстройств, активно обсуждаются клинические и психолого-социальные границы феномена, динамика отчуждения и взаимосвязь с другими психическими нарушениями.

Так, еще в 1873 г. M. Krishaber [23] обратил внимание на синдром, выделенный и обозначенный им как «цереброкардиальная невропатия», проявляющийся переживанием отчуждения своей личности. Термин «деперсонализация» впервые был предложен L. Dugas [20] в 1898 г., утверждавшим «чувство» изменения Эго, впоследствии обозначенного автором как «чувство потери себя». P. Schilder [26] в монографии, изданной в 1914 г., описывал деперсонализационный синдром как состояние, при котором наблюдается не только ощущение измененности индивидуума, но и окружающего мира. К. Haug [21] в 1936 г. признавал в структуре деперсонализации расстройства, выражающиеся в отчуждении собственного тела или органов.

Позже в 1954 г. В. Ackner указал на «второстепенные» признаки деперсонализации в форме затрудненного осмышления и нарушенной концентрации внимания, ухудшения памяти, бедности представлений [17]. Анализ взаимоотношения деперсонализационных и аффективных нарушений активно обсуждался Ю.В. Каннабихом (1914), B. Ackner (1954) [7, 17, 18].

В систематизации деперсонализационных расстройств особенно значима заслуга К. Haug. Основываясь на теории Вернике о трех сферах психической деятельности, он выделял аутопсихический, соматопсихический и аллопсихический типы деперсонализации, проявляющиеся соответственно в от- 
чуждении психического «Я», телесного «Я» и окружающей действительности. Обозначенные им варианты до настоящего времени рассматриваются в современных психиатрических классификациях [21].

Е.Б. Беззубова (1985) добавила к этим вариантам так называемую витальную деперсонализацию. Согласно ее определению, витальная деперсонализация является переживанием неясной измененности, отчужденности самоощущения, «внутреннего разлада», «физического неуюта» [3].

На современном этапе психиатрических знаний многие ведущие исследователи также предпринимали попытки создания психопатологической типологии деперсонализационных расстройств в структуре отдельных нозологических форм. Так, А.Б. Смулевич и В.Ю. Воробьев (1973) разделили все проявления деперсонализации на чувственные, идеаторные и занимающее промежуточное место между первыми и вторыми [9].

К исследованию деперсонализации с позиций расстройств определенных функций личности подошел С. Scharfetter (1991) [27]. Развивая представления К. Ясперса (1959) и К. Шнайдера (1967) относительно компонентов самосознания, С. Scharfetter (1991) предлагал выделять пять составляющих самосознания: 1) сознание витальности - наиболее базисная структура самосознания, переживается в виде ощущения своего существования как живого организма; 2) сознание активности переживается в виде сознания принадлежности себе своих психических процессов; 3) сознание целостности - переживание себя как единого существа с единым «Я»; 4) сознание границ «Я» - разделение между «Я» и окружающим, фантазией и объектами реального мира. 5) сознание идентичности «Я» - психического и телесного.

Выпадению каждого компонента самосознания соответствует то или иное проявление деперсонализации. Например, исчезновение границ «Я» подразумевает «страхи потери контроля» и дереализацию. Концепция C. Scharfetter построена на модели самосознания как явления сугубо психологического, а расстройства основных параметров самосознания и составляют основу деперсонализационных расстройств [27].

Большинство современных исследователей обращают внимание на то обстоятельство, что деперсонализационные расстройства редко наблюдаются изолировано. Более того, данные расстройства обычно возникают в комплексе с определенными психопатологическими феноменами, образуя достаточно сложные симптомокомплексы. Особенно часто отмечается взаимосвязь деперсонализации с аффективными расстройствами [5, 6, 10, 12, 13, 24].

Так, В.Н. Краснов (2011) считает наиболее характерным сочетание деперсонализационных расстройств с депрессивными нарушениями, подчеркивая особую связь деперсонализации с аффектом тревоги [8].
Тем не менее имеются сообщения о возможном сочетании деперсонализации с гипоманиакальным аффектом [14].

Особый интерес представляют описания сочетаний деперсонализации с обсессивно-фобическими и сенестопатическими расстройствами, представленные в работах А.В. Снежневского (1987), А.Б. Смулевича, Э.Б. Дубницкой (1997) [10, 12].

Некоторые исследователи отмечают, что деперсонализация часто сопровождается ипохондрической симптоматикой $[2,3,9,13]$. Также убедительными выглядят результаты исследований, доказывающих негативное влияние тяжести текущей депрессии, оцененной интегративно по шкале CGI-S, на субъективную оценку уровня социальной адаптации у пациентов с коморбидными аффективными и личностными расстройствами. В случае коморбидности с другими психическими расстройствами депрессия отличается более частым повторением фаз, более поздней выявляемостью в сравнении с депрессией без указанной коморбидности $[18,22$, 25].

Следует отметить, что в рамках синдрома деперсонализации в структуре депрессии остаются недостаточно изученными как особенности психопатологии, так и дифференциальной диагностики, прогностической оценки. В то же время нуждается в уточнении психопатологическая структура феномена, отсутствует единая общепринятая типология данных расстройств.

Цель исследования - установление психопатологической структуры эндогенных депрессий с деперсонализационными расстройствами, разработка их типологии, выявление связи явлений деперсонализации с другими психопатологическими феноменами.

\section{МАТЕРИАЛЫ И МЕТОДЫ}

В соответствии с целью и задачами работы было изучено 57 больных, в том числе 38 женщин (средний возраст $36,89 \pm 12,9$ года) и 19 мужчин (средний возраст $37,11 \pm 13,7$ года).

Критерии включения: пациенты обоего пола, возраст на момент обследования 18-70 лет, наличие деперсонализационных расстройств в структуре состояния, депрессивное состояние, соответствующее критериям рубрик F31-34 МКБ-10.

Критерии исключения: 1) возраст моложе 18 лет и старше 70 лет; 2) наличие в статусе симптомов, выходящих за рамки аффективного регистра (острый чувственный бред, галлюцинаторные и кататонические расстройства), достигающих значительной степени выраженности и на момент проведения обследования определяющих состояние больных; 3) наличие соматических и неврологических заболеваний в стадии декомпенсации; 4) наличие судорожной активности на ЭЭГ; 5) наличие признаков тяжелого органического поражения центральной нервной системы (ЦНС); 6) злоупотребление алкоголем и ПАВ. 
Основным был клинико-психопатологический метод исследования. В случаях, где это было возможно, проводилось катамнестическое исследование с целью уточнения особенностей дальнейшей динамики деперсонализационных расстройств и заболевания в целом при длительно текущих депрессиях. Длительность катамнеза составляла от 6 месяцев до 7 лет, при этом у 3 больных его продолжительность не превышала 1 года, у 10 больных составила от 1 до 3 лет, у 8 пациентов варьировала от 4 до 7 лет. У всех больных изучалось также соматическое и неврологическое состояние, а также проводилось ЭЭГ-обследование для исключения признаков судорожной активности.

\section{РЕЗУЛЬТАТЫ И ОБСУЖДЕНИЕ}

С целью дополнения клинических характеристик деперсонализации были выделены 3 феномена: отчуждения, утраты и изменения. Все эти феномены имели место в рамках всех видов деперсонализации (ауто-, сомато- и аллопсихической).

Феномен отчуждения проявлялся нарушением самоидентификации и был представлен в чувственном переживании больных того, что прежние психические функции, тело, включенность в окружающее стали иными, не свойственными им в обычном состоянии. Пациенты предъявляли жалобы на то, что все тело или какая-то его часть стали чужими. Они не узнавали звука своего голоса, отражения в зеркале, себя на фотографии, говорили о своих действиях и мышлении - «как будто это не я», рассказывали о не свойственном им ранее восприятии окружающего - не чувствовали перемены времен года, не ощущали хода времени.

Феномен утраты заключался в переживании пациентами частичной или полной потери чувств, эмоций, телесных ощущений, собственного «Я», ряда психических функций (мышления, воли). Больные регистрировали у себя ощущение пустоты или онемения в различных частях тела, внутренних органах, мыслях, в душе. В описании жалоб пациентов преобладали сравнения - «я стал как тупой», «я как Марья-искусница из сказки: Что воля, что неволя - все равно», «мои руки как будто пустые», «я не чувствую, что сплю, как будто голова всегда свежая, как будто я никогда не устаю», «Я не чувствую себя, как будто внутри меня ничего нет».

Феномен изменения был представлен переживанием пациентами необычного самоощущения. Это проявлялось появлением различных ощущений в виде легкости, тяжести, напряжения или как общее неопределенное неясное и трудноописуемое чувство внутреннего дискомфорта, разлада, психического и физического неуюта, которое либо тотально охватывало все сферы психической деятельности (психическое «Я», физическое «Я» и восприятие окружающей действительности): «со мной чтото не так», «я как будто умираю», либо избирательно затрагивало 1-2 из этих сфер: «я все не так, как раньше вижу, не так четко», «я чувствую себя странно и все вокруг, как в тумане»».
В ходе исследования в зависимости от клиникодинамических характеристик деперсонализационных расстройств в рамках эндогенных депрессий были выявлены 3 типологических варианта:

1. Депрессия с пароксизмальной деперсонализацией (26 наблюдений, 19 женщин, 7 мужчин, средний возраст $38,1 \pm 14,9$ года). В данной группе явления деперсонализация носила пароксизмальный характер, сопровождались выраженным аффектом тревоги, массивными вегетативными проявлениями в виде телесной дрожи, тошноты, потливости, сердцебиения и имели клинические характеристики феноменов изменения или отчуждения. Деперсонализационные симптомы наблюдались на протяжении от нескольких секунд до 1-2 дней, описывались пациентами как «приступ», который имел внезапное начало, быстро достигал пика интенсивности и так же внезапно прекращался самопроизвольно или на фоне применения анксиолитических препаратов.

Впервые возникшее подобное состояние заставляло пациентов прибегать к помощи врачей, вызывать бригады СМП, многократно измерять артериальное давление и пульс. Даже после окончания «приступа» сохранялась тревога за свое здоровье, больные проходили обследование у неврологов и кардиологов. Отсутствие объективных диагностических данных, как правило, не убеждало пациентов в отсутствии соматического заболевания. Быстро развивалась ипохондрическая симптоматика. Часто прослеживалась четкая связь между возникновением первого пароксизма с предшествующей психотравмирующей ситуацией или длительным пребыванием пациента в состоянии психоэмоционального напряжения. Весь комплекс деперсонализационных расстройств обнаруживал четкую корреляцию с аффектом тревоги, что проявлялось в синхронных с аффектом колебаниях интенсивности деперсонализационных жалоб. В целом усиление или возникновение тревоги обычно предшествовало возникновению деперсонализационных расстройств, «приступы» по своей структуре были идентичны, однотипны. Пациенты отмечали, что первый по счету приступ являлся самым тяжелым, последующие переносились субъективно легче, пациенты как бы «привыкали» к наличию приступов. В то же время в периоды между «приступами» пациенты обнаруживали хорошее понимание природы происхождения симптомов, но на высоте тревоги критичность значительно снижалась, больные стремились получить немедленную медицинскую помощь, злоупотребляли кардиологическими препаратами (такими как валидол, валокордин), транквилизаторами, принимая их в высоких дозах. В межприступные периоды во всех случаях отмечались высокий уровень внутреннего напряжения, самоконтроля, «ожидание приступа», стремление избежать длительное общение с другими людьми, сниженное настроение, что сами пациенты считали логическим следствием наличия «приступов». Сходные состояния были описаны Г.О. Чиковани [7]. 
2. Депрессия с затяжной деперсонализацией (17 наблюдений, 10 женщин, 7 мужчин, средний возраст 39,8 $\pm 11,5$ года).

При затяжном варианте деперсонализационных расстройств наблюдались депрессивные состояния длительностью от 1 месяца до 3 лет. Начало депрессии характеризовалось наличием промежутка сниженного настроения с «классической триадой», наличием в структуре тревоги, соматическими проявлениями депрессии в виде нарушений сна и аппетита. В 53\% случаев депрессия имела психогенный запуск, но связь с психогенией быстро утрачивалась. Отмечалось нарастание уровня тревоги на протяжении 2-3 недель от начала депрессии, следом манифестировали деперсонализационные симптомы, которые носили непрерывный характер на протяжении всего времени течения депрессии и соответствовала клиническим проявлениям феномена изменения. Редукция деперсонализационных расстройств происходила одновременно с угасанием собственно тимического компонента депрессии. Примечательно, что, возникнув в структуре депрессии, деперсонализационные расстройства становились центральной жалобой пациента, субъективно оценивались как наиболее тягостное ощущение из всех имеющихся симптомов.

3. Депрессия с хронической деперсонализаџией (14 наблюдений, 6 женщин, 8 мужчин, средний возраст $31,14 \pm 9,4$ года).

В рамках хронического течения деперсонализационных расстройств наблюдались состояния длительностью более 3 лет. В анамнезе у пациентов с данным типом течения деперсонализационных расстройств выявлен этап наличия серии пароксизмальноподобных состояний с массивной вегетативной симптоматикой, страхом смерти, возникающим на высоте тревожного «приступа». Пароксизмы следуют друг за другом, как «клише», постепенно увеличивается частота их возникновения, нарастает уровень межприступной тревоги.

Завершающим данный этап развития деперсонализационных расстройств возникает «самый тяжелый», по оценке самих пациентов, «приступ», который по продолжительности превосходит все предыдущие, длится от нескольких часов до 1,5 суток, характеризуется высочайшим уровнем тревоги, преимущественно идеаторным её компонентом, выраженным вегетативным симптомокомплексом. По окончании вышеописанного пароксизмального состояния угасает уровень тревоги, появляется деперсонализационная симптоматика, которая приобретает непрерывный монотонный характер течения, воспринимается, как самый мучительный симптом болезни. Больные не испытывают острой тоски, не оценивают свое настроение как особенно сниженное, считают снижение настроения прямым следствием их мучительных ощущений. Деперсонализационные симптомы становятся жалобой первого плана, имеют клинические характеристики феноменов изменения и (или) утраты.
Выявляется суточный ритм колебаний настроения с небольшим улучшением в вечерние часы. Депрессия на данном этапе начинает носить оттенок астеноподобной, характеризуется наличием жалоб на слабость, быструю утомляемость, трудности сосредоточения внимания, раздражительность, гиперчувствительность к громким звукам. Редукция депрессивных симптомов в ходе лечения не приводила к полному угасанию деперсонализационных симптомов, отмечалось лишь снижение их интенсивности. Примечательно, что на фоне проводимой терапии антипсихотиками у пациентов с хроническим типом течения деперсонализационных расстройств менялся полюс аффекта с депрессивного на гипоманиакальный. Несмотря на это, деперсонализационные жалобы сохранялись, хотя и становились субъективно менее актуальными. Часто у пациентов симптомы отмечались в течение многих лет, даже на фоне проводимого лечения. Выхода в ремиссию с полным восстановлением личностных свойств и уровня социально-трудовой адаптации не наблюдалось. Характерной особенностью у таких больных стало появление по мере течения заболевания своеобразной сверхценной ипохондрии. Пациенты, зная о своем диагнозе, с увлечением читали медицинскую литературу о деперсонализации, начинали вести «особый» образ жизни, позволяющий исключить факторы, усиливающие симптомы заболевания, аккуратно принимали назначенные препараты, не тяготились длительным пребыванием в стационаре.

\section{ЗАКЛЮЧЕНИЕ}

Депрессия с деперсонализационными расстройствами является нозологически неспецифичной, обнаруживая психопатологическую и клиническую неоднородность. Катамнестическое исследование позволило точнее определить нозологическую принадлежность депрессивных стояний. У 40 пациентов диагностировано рекуррентное депрессивное расстройство, у 17 пациентов - биполярное аффективное расстройство. Наличие деперсонализационных расстройств в ряде случаев расценивается как прогностически неблагоприятный признак. Имеют значение выраженность расстройств и комбинация различных клинических вариантов деперсонализации, представленных в рамках одного состояния

Выявление деперсонализационных расстройств в структуре синдромокомплекса свидетельствует о склонности к затяжному характеру течения (82\% наблюдений) и обнаруживает резистентность к лекарственной терапии.

Деперсонализационные жалобы являются центральным звеном всех спонтанных высказываний пациента, на них сосредоточено внимание больного на всем протяжении лечения.

В анамнезе пациентов нередко еще на доклиническом этапе определяются редкие краткосрочные единичные эпизоды деперсонализации, возникавшие на фоне переутомления, влияния патогенных стрессовых факторов, в форме неясных ощущений неопределенной внутренней измененности. 
Проведенный анализ психопатологической структуры эндогенных депрессий с деперсонализацией свидетельствовал о большом клиническом разнообразии её проявлений даже в пределах одного и того же варианта. При нарастании тяжести, глубины, длительности и частоты возникновения депрессивных эпизодов наблюдалась пропорциональное усиление деперсонализационных расстройств. Развитие деперсонализационных симптомов нередко сопровождалось появлением нарушений тревожного спектра.

Таким образом, можно по-прежнему утверждать высокую актуальность исследований деперсонализационных расстройств из-за недостаточной изученности проблемы. Об этом свидетельствуют многочисленные публикации как отечественных, так и зарубежных исследователей, посвященные клинике, патогенезу и лечению деперсонализации. Накопление подобных данных, очевидно, должно способствовать решению главной задачи - раскрытию патогенетических механизмов и эффективному поиску оптимизации методов лечения и профилактики обозначенного расстройства.

\section{КОНФЛИКТ ИНТЕРЕСОВ}

Авторы заявляют об отсутствии конфликта интересов в связи с публикацией данной статьи.

\section{ИСТОЧНИК ФИНАНСИРОВАНИЯ}

Авторы заявляют об отсутствии финансирования при проведении исследования.

\section{СООТВЕТСТВИЕ ПРИНЦИПАМ ЭТИКИ}

Исследование проведено с соблюдением норм современной биомедицинской этики и этических стандартов, разработанным в соответствии с Хельсинской декларацией ВМА (протокол заседания этического комитета ФГБОУ ВО «Уральский государственный медицинский университет» Минздрава РФ № 3 от 06.04.2007).

\section{ЛИТЕРАТУРА}

1. Ахапкина М.В. Психопатология и клиника деперсонализационных расстройств при шизофрении: автореф. дис. ... канд. мед. наук. М., 1993: 24.

2. Баранов П.А. Психопатология анестетических депрессий в клинике приступообразно-прогредиентной шизофрении: автореф. дис. ... канд. мед. наук. М., 1989: 24.

3. Беззубова Е.Б. Деперсонализация как расстройство развития самосознания. Журнал невропатологии и психиатрии им. С.С. Корсакова. 1993; 93: 3.

4. Васильева С.Н., Симуткин Г.Г., Счастный Е.Д. Клиникодинамические характеристики биполярного аффективного расстройства при коморбидности с другими психическими расстройствами. Сибирский вестник психиатрии и наркологии. 2017; 2 (95): 16-20.

5. Вертоградова О.П., Целищев О.В. Депрессивные идеи в структуре непсихотической депрессии у больных аффективными расстройствами и факторы риска их развития. Сoциальная и клиническая психиатрия. 2011; 4: 14-19.
6. Ильина Н.А. Психопатология деперсонализационной депрессии. Журнал неврологии и психиатрии им. С.С. Корсакова. 1999; 7: 21-26.

7. Каннабих Ю.В. Циклотимия, ее симптоматология и течение. М., 1914.

8. Краснов В.Н. Расстройства аффективного спектра. М.: Практическая медицина, 2011: 432.

9. Смулевич А.Б., Воробьев В.Ю. Деперсонализация (клиникопсихопатологические аспекты). Журнал невропатологии и психиатрии им. С.С. Корсакова. 1973; 73 (8): 1242-1252.

10. Смулевич А.Б., Дубницкая Э.Б., Тхостов А.Ш. и др. Психопатология депрессий (к построению типологической модели). Депрессии и коморбидные расстройства. М., 1997: 2853.

11. Смулевич А.Б. Депрессии в общей медицине: Руководство для врачей. М.: МИА, 2001: 256.

12. Смулевич А.Б. Психические расстройства в клинической практике / Под ред. А.Б. Смулевича. 2-е изд. М.: МЕДпрессинформ, 2012: 720.

13. Нуллер Ю.Л. Депрессия и деперсонализация. Л.: Медицина, 1981: 207

14. Фридман Б.Д. К учению о деперсонализации. Труды психиатрической клиники I Московского медицинского института, посвященные памяти П.Б. Ганнушкина. Выпуск IV. М., Л., 1934.

15. Чернышева К.Г. Клинико-динамические аспекты «двойной» депрессии. Сибирский вестник психиатрии и наркологии. 2011; 1 (64): 36-37.

16. Чиковани Г.О. Психопатология пароксизмальноподобных расстройств при эндогенных психических заболеваниях. Журнал невропатологии и психиатрии им. С.С. Корсакова. 1997; 97 (4): 30-34.

17. Ackner B. Depersonalization: 1. Aetiology and phenomenology. Journal of Mental Science. 1954; 100: 838-853.

18. Ackner B. Depersonalization: II. Clinical syndromes. Journal of Mental Science. 1954; 100: 854-872.

19. Angst J., Gamma A., Pezawas L., et al. Parsing the clinical phenotype of depression: the need to integrate brief depressive episodes. Acta Psychiatr. Scand. 2007; 115 (3): 221-228.

20. Dugas L. Un cas de depersonnalisation. Revue philosophic de la France et de l'etranger. 1898. 23: 500.

21. Haug K. Die Störungen des Personlichkeitsbewusstseins und verwandte Entfremdungserlebnisse. Stuttgart, 1936.

22. Kessler R.C., Chiu W.T., Demler O., et al. Prevalence, severity and comorbidity of 12-onth DSM-IV disorders in NCSR. Arch. Gen. Psychiatr. 2005: 617-627.

23. Krishaber M. De la Nervopathie cerebrocardiaque. Gazette Science Medecine. Bordeaux, 1872.

24. Mayer-Gross W.W. On depersonalization. British Journal of Medical Psychology. 1955; 15: 103-122.

25. Medford N., Sierra M., Baker D., David A.S. Understanding and treating depersonalisation disorder. Advances in Psychiatric Treatment. 2005; 11: 92-100.

26. Schilder P. Depersonalization. In Introduction to psychoanalytic psychiatry. Nerv. Ment. Dis. Monographies. Series. 1928; 50: 120 .

27. Scharfetter C. Allgemeine Psychopathologie. New York: Georg Thieme, Stuttgart: Verlag, 1991: 332.

28. Waraich P., Goldner E.M., Somers J.M., Hsu L. Prevalence and incidence studies of mood disorders: a systematic review of the literature: Canadian Journal of Psychiatry. 2004; 49 (2): 124-138.

Поступила в редакцию 6.10.2017 Утверждена к печати 30.10.2017

Деменева Анна Андреевна, заведующая женским психиатрическим отделением.

Ретюнский Константин Юрьевич, д.м.н., профессор, заведующий кафедрой психиатрии.

Ретюнский Константин Юрьевич, retiunsk@ mail.ru 
For citation: Demeneva A.A., Retyunsky K.Yu. Psychopathological differentiation of depersonalization disorders in the endogenous depression. Siberian Herald of Psychiatry and Addiction Psychiatry. 2017; 4 (97): 31-37. https://doi.org/10.26617/1810-3111-2017-4(97)31-37

\title{
Psychopathological differentiation of depersonalization disorders in the endogenous depression
}

Demeneva A.A. ${ }^{1}$, Retyunsky K.Yu. ${ }^{2}$

\author{
${ }^{1}$ Sverdlovsk Regional Clinical Psychiatric Hospital \\ Sibirsky Trakt ${ }^{\text {th }}$ km, 620030, Yekaterinburg, Russian Federation \\ ${ }^{2}$ Ural State Medical University \\ Repin Street 3, 620028, Yekaterinburg, Russian Federation
}

\section{ABSTRACT}

Objective was - to identify the psychopathological structure of endogenous depressions with depersonalization disorders, to develop their typology, to develop the connection of the phenomena of depersonalization with other psychopathological phenomena. Material and methods. A study was conducted between 2006 and 2014 on the base of department for the study of endogenous mental disorders and affective states of the scientific center of mental health and at the department of psychiatry. As the criterion of the selection of patients the presence of depersonalization disorders in the clinical picture of the endogenous depressions served (F31-34). With clinical-psychopathological and clinical-catamnestic methods 57 patients were examined (38 women and 19 men). The mean age of patients up to the moment of examination was $36.9 \pm 13.0$ years. Results. Depending on the clinical-dynamic characteristics of the depersonalization disorders within the framework of endogenous depressions 3 typological variants of the states being investigated were isolated: paroxysmal, protracted and chronic.

Keywords: endogenous depression, depersonalization, typology, dynamic.

\section{REFERENCES}

1. Akhapkina M.V. Psihopatologiya i klinika depersonalizatsionnyih rasstroystv pri shizofrenii [Psychopathology and clinics of depersonalization disorders in schizophrenia]. Avtoref. dis. ... kand. med. nauk - Abstract of PhD thesis. M., 1993: 24 (in Russian).

2. Baranov P.A. Psihopatologiya anesteticheskih depressiy v klinike pristupoobrazno-progredientnoy shizofrenii [Psychopathology of anesthetic depressions in the clinical picture of shift-like schizophrenia]. Avtoref. dis. ... kand. med. nauk - . Abstract of PhD thesis. M.,1989: 24 (in Russian).

3. Bezzubova E.B. Depersonalizatsiya kak rasstroystvo razvitiya samosoznaniya [Depersonalization as a disorder of development of self-consciousness]. Zhurnal nevropatologii $i$ psihiatrii im. S.S. Korsakova - S.S. Korsakov Journal of Neuropathology and Psychiatry. 1993; 93: 3 (in Russian).

4. Vasilieva S.N., Simutkin G.G., Schastnyy E.D. Klinikodinamicheskie harakteristiki bipolyarnogo affektivnogo rasstroystva pri komorbidnosti $\mathrm{s}$ drugimi psihicheskimi rasstroystvami [Clinical-dynamic characteristics of bipolar affective disorder comorbid with mental disorders]. Sibirskiy vestnik psihiatrii i narkologii - Siberian Herald of Psychiatry and Addiction Psychiatry. 2017; 2 (95): 16-20 (in Russian).

5. Vertogradova O.P., Tselischev O.V. Depressivnyie idei v strukture nepsihoticheskoy depressii u bolnyih affektivnyimi rasstroystvami i faktoryi riska ih razvitiya [Depressive ideas in the structure of non-psychotic depressions in patients with affective disorders and risk factors for their development]. Sotsialnaya $i$ klinicheskaya psihiatriya - Social and Clinical Psychiatry. 2011; 4: 14-19 (in Russian)

6. Ilina N.A. Psihopatologiya depersonalizatsionnoy depressii [Psychopathology of depersonalization depression]. Zhurnal nevrologii i psihiatrii im. S.S. Korsakova - S.S. Korsakov Journal of Neurology and Psychiatry. 1999; 7: 21-26 (in Russian).

7. Kannabikh Yu.V. Tsiklotimiya, ee simptomatologiya i techenie [Cyclothymia, its symptomatology and course]. M., 1914 (in Russian).

8. Krasnov V.N. Rasstroystva affektivnogo spektra [Affective spectrum disorders]. M.: Prakticheskaya meditsina, 2011: 432 (in Russian).

9. Smulevich A.B., Vorobyev V.Yu. Depersonalizatsiya (klinikopsihopatologicheskie aspektyi) [Depersonalization (clinicalpsychopathological aspects]. Zhurnal nevropatologii i psihiatrii im. S.S. Korsakova - S.S. Korsakov Journal of Neuropathology and Psychiatry. 1973; 73 (8): 1242-1252 (in Russian).

10. Smulevich A.B., Dubnitskaya E.B., Tkhostov A.Sh. i dr. Psihopatologiya depressiy ( $\mathrm{k}$ postroeniyu tipologicheskoy modeli). Depressii i komorbidnyie rasstroystva [Psychopathology of depressions (to constructing a typological model). Depressions and comorbid disorders. M., 1997: 28-53 (in Russian).

11. Smulevich A.B. Depressii v obschey meditsine: Rukovodstvo dlya vrachey [Depressions in general medicine: Handbook for physicians]. M.: MIA, 2001: 256 (in Russian).

12. Smulevich A.B. Psihicheskie rasstroystva $v$ klinicheskoy praktike [Mental disorders in clinical practice]. A.B. Smulevich, ed.. 2-e izd. M.: MEDpress-inform, 2012: 720 (in Russian).

13. Nuller Yu.L. Depressiya i depersonalizatsiya [Depression and depersonalization]. L.: Meditsina, 1981: 207 (in Russian).

14. Fridman B.D. K ucheniyu o depersonalizatsii [To doctrine of depersonalization]. Trudyi psihiatricheskoy kliniki Pervogo Moskovskogo meditsinskogo instituta, posvyaschennyie pamyati P.B. Gannushkina. Vyipusk IV. M., L., 1934 (in Russian).

15. Chernysheva K.G. Kliniko-dinamicheskie aspektyi «dvoynoy» depressii [Clinical-dynamic aspects of "dual" depression]. Sibirskiy vestnik psihiatrii i narkologii - Siberian Herald of Psychiatry and Addiction Psychiatry. 2011; 1 (64): 36-37 (in Russian).

16. Chikovani G.O. Psihopatologiya paroksizmalnopodobnyih rasstroystv pri endogennyih psihicheskih zabolevaniyah [Psychopathology of paroxysm-like disorders in endogenous mental diseases]. Zhurnal nevropatologii i psihiatrii im. S.S. Korsakova S.S. Korsakov Journal of Neuropathology and Psychiatry. 1997; 97 (4): 30-34 (in Russian).

17. Ackner B. Depersonalization: 1. Aetiology and phenomenology. Journal of Mental Science. 1954; 100: 838-853.

18. Ackner B. Depersonalization: II. Clinical syndromes. Journal of Mental Science. 1954; 100: 854-872.

19. Angst J., Gamma A., Pezawas L., et al. Parsing the clinical phenotype of depression: the need to integrate brief depressive episodes. Acta Psychiatr. Scand. 2007; 115 (3): 221-228.

20. Dugas L. Un cas de depersonnalisation. Revue philosophic de la France et de l'etranger. 1898. 23: 500.

21. Haug K. Die Störungen des Personlichkeitsbewusstseins und verwandte Entfremdungserlebnisse. Stuttgart, 1936.

22. Kessler R.C., Chiu W.T., Demler O., et al. Prevalence, severity and comorbidity of 12-onth DSM-IV disorders in NCSR. Arch. Gen. Psychiatr. 2005: 617-627. 
23. Krishaber M. De la Nervopathie cerebrocardiaque. Gazette Science Medecine. Bordeaux, 1872.

24. Mayer-Gross W.W. On depersonalization. British Journal of Medical Psychology. 1955; 15: 103-122.

25. Medford N., Sierra M., Baker D., David A.S. Understanding and treating depersonalisation disorder. Advances in Psychiatric Treatment. 2005; 11: 92-100.

26. Schilder P. Depersonalization. In Introduction to psychoanalytic psychiatry. Nerv. Ment. Dis. Monographies. Series. 1928; 50: 120.

Demeneva Anna A., Head of Psychiatric Ward for Women, Sverdlovsk Regional Clinical Psychiatric Hospital, Yekaterinburg, Russian Federation. Retyunsky Konstantin Yu., MD, Professor, Head of Psychiatry Department, Ural State Medical University, Yekaterinburg, Russian Federation.
27. Scharfetter C. Allgemeine Psychopathologie. New York: Georg Thieme, Stuttgart: Verlag, 1991: 332.

28. Waraich P., Goldner E.M., Somers J.M., Hsu L. Prevalence and incidence studies of mood disorders: a systematic review of the literature: Canadian Journal of Psychiatry. 2004; 49 (2): 124138 .

Received October 6.2017 Accepted October 30.2017

$\triangle$ Retyunsky Konstantin Yu., retiunsk@mail.ru 